\title{
SARS-CoV accessory protein 7 a directly interacts with human LFA-1
}

\author{
Karen Hänel' ${ }^{1}$ and Dieter Willbold1,2,* \\ ${ }^{1}$ Forschungszentrum Jülich, INB-2, D-52425 Jülich, \\ Germany \\ ${ }^{2}$ Institut für Physikalische Biologie and BMFZ, Heinrich- \\ Heine-Universität, D-40225 Düsseldorf, Germany \\ ${ }^{*}$ Corresponding author \\ e-mail: dieter.willbold@uni-duesseldorf.de
}

\begin{abstract}
The SARS-CoV accessory protein $7 \mathrm{a}$ is a type I membrane protein with an extracellular domain of 81 amino acid residues. It is described to be expressed during infection and to be a component of the virus particle surface. In this study, we demonstrate that protein $7 a$ binds directly and specifically to human lymphocyte function-associated antigen 1 (LFA-1) on the cell surface of Jurkat cells. The binding is increased upon artificial cell activation with phorbol ester. These observations are confirmed by direct in vitro binding of recombinant protein $7 \mathrm{a}$ to the wild type and mutant K287C/K294C I domain showing that the I domain is the 7 a binding site in the $\alpha_{L}$ chain of LFA-1. Consequences of the LFA-1 interaction with $7 \mathrm{a}$ are discussed. In particular, our data suggest LFA-1 to be an attachment factor or the receptor for SARS-CoV on human leukocytes.
\end{abstract}

Keywords: CD11a/CD18; ICAM; post-infective downregulation; receptor; T lymphocytes; viral entry.

\section{Introduction}

A novel coronavirus (CoV) has been shown to be the etiologic agent of the severe acute respiratory syndrome (SARS) epidemic, which affected thousands of people from November 2002 to July 2003. The viral positivestrand RNA genome is almost $30 \mathrm{~kb}$ in length and contains 14 potential open reading frames. The characteristic features of coronaviruses are two overlapping open reading frames (ORF1a and ORF1b) that code for the 'replicase', which is further processed into non-structural proteins, and four ORFs that code for the structural proteins spike, membrane, envelope and nucleocapsid (Marra et al., 2003; Rota et al., 2003). The eight ORFs for subgroup-specific accessory proteins are thought to be dispensable for viral replication in cell culture (Yount et al., 2005), but may be important for virus-host interactions, and thus contribute to the virus fitness and the viral pathogenesis in the natural host (de Haan et al., 2002; Ortego et al., 2003; Haijema et al., 2004).

The accessory protein 7 a (also known as X4 or U122) is a type I membrane protein of 122 amino acids. It contains an amino-terminal signal sequence, which is cleaved off between residues 15 and 16, an ectodomain (residues 16-98), a transmembrane helix comprising residues 99-117, and a short intracellular part of only five residues. This carboxy-terminus (KRKTE) represents a functional endoplasmic reticulum (ER) retrieval motif. The major part of the protein is a hydrophilic ectodomain that is oriented inside the lumen of the ER/Golgi or on the surface of either the cell membrane or the virus particle, depending on the localization of the protein. Experiments to investigate the subcellular localization in Vero E6 cells show that $7 \mathrm{a}$ is present in the ER compartment, probably in the ER/Golgi intermediate compartment (Fielding et al., 2004), the trans-Golgi network and also on the cell surface of infected cells (Chen et al., 2005; Nelson et al., 2005). Recently, it was shown that $7 a$ is contained in viral particles (Huang et al., 2006a).

So far, only one host protein, the cellular small glutamine-rich tetratricopeptide repeat-containing protein SGT (Fielding et al., 2006) was shown to interact with protein $7 \mathrm{a}$. SGT has been shown to be involved in many cellular processes including cell cycle control, transcription and splicing events, protein transport and protein folding (Blatch and Lassle, 1999). Whether there is a biological significance of the interaction between $7 \mathrm{a}$ and SGT remains to be elucidated. In addition to SGT, two SARS-CoV proteins were shown to interact with 7a, namely the Spike protein (Huang et al., 2006a) and protein 3a (Tan et al., 2004b).

It was reported that $7 \mathrm{a}$ is able to induce apoptosis via the caspase pathway in various cell types (Tan et al., 2004a; Kopecky-Bromberg et al., 2006). Also, protein 7a is able to block cell cycle progression at the G0/G1 phase by reducing the expression levels of cyclin D3 and phosphorylation of retinoblastoma protein (Yuan et al., 2006). Furthermore, overexpression of protein $7 a$ inhibits cellular protein synthesis and induces the phosphorylation and activation of p38 mitogen-activated protein kinase (Kopecky-Bromberg et al., 2006). Recently, it was shown that $7 \mathrm{a}$ is able to activate nuclear factor $\kappa \mathrm{B}$ and c-Jun N-terminal kinase, and to enhance interleukin promoter activity (Kanzawa et al., 2006).

The three-dimensional structure of the 7 a ectodomain has been solved by X-ray crystallography (Nelson et al., 2005) and nuclear magnetic resonance (NMR) (Hanel et al., 2006). It represents a novel variation of the immunoglobulin like $\beta$-sandwich fold. Because $7 a$ does not reveal significant sequence homologies to proteins in the databases, a structure based similarity search for proteins with known function was carried out. We found a high structural similarity of the 7a ectodomain to the D1 domain of ICAM-1. In addition, we analyzed the 7a ectodomain structure in more detail and found additional elements of the interaction interface between ICAM-1 D1 domain and LFA-1 I domain to be present in 7a as well, e.g., the characteristic glutamic acid residue that is sur- 
rounded by a ring of hydrophobic residues. Based on these findings we predicted $7 \mathrm{a}$ to possess binding activity for the $\alpha_{\mathrm{L}}$ integrin I domain of LFA-1 (Hanel et al., 2006).

ICAMs are cell adhesion molecules expressed on the surface of cells, especially on endothelial cells after cytokine-mediated stimulation at inflammatory sites. ICAMs belong to a subset of Ig-like superfamily proteins, which are specialized for binding to integrins. Integrins, in general, are non-covalently associated $\alpha / \beta$ heterodimeric transmembrane proteins, which are involved in adhesive cell-cell interactions. ICAM-1 and ICAM-2 are known to specifically interact with lymphocyte functionassociated antigen 1 (LFA-1, CD11a/CD18, $\alpha_{\llcorner} \beta_{2}$ integrin) that is expressed exclusively on leucocytes. Interactions between ICAMs and LFA-1 play a crucial role in lymphocyte homing to inflammation sites and in various intercellular cooperations during the specific immune response.

LFA-1 is reported to exist in three different conformations (Kinashi, 2006; Nishida et al., 2006). A bent or switchblade-like conformation with the headpiece, which is responsible for ligand-binding, in close proximity to the membrane shows low-affinity to the ligand and is referred to as the 'bent' or 'low affinity' state. The other two forms of LFA-1 have an extended conformation, whereas the receptor including the headpiece is upright. In this upright orientation, the headpiece adopts either a 'closed' state with intermediate affinity or an 'open' state with high affinity to the ligand.

The ICAM binding site of LFA-1 is contained within the 180 residue I domain of the headpiece of LFA-1. A characteristic feature of the I domain is the metal ion-dependent adhesion site with a divalent metal ion coordinated by acidic residues of the I domain and the ligand (Hynes, 2002). Recombinant I domain represents the closed form. To investigate the open form, a pair of cystein residues was introduced to form a disulfide bridge that locks the activated form (Shimaoka et al., 2001). This I domain mutant, which mimics the active conformation, shows 10000 -fold increased affinity for ICAM (Shimaoka et al., 2001, 2003).

To prove or disprove the structure based prediction that SARS-CoV protein 7 a binds to the I domain of the $\alpha_{L}$ subunit of LFA-1, we carried out a series of experiments using recombinant protein $7 \mathrm{a}$ and recombinant wild type and mutant LFA-1 I domain, as well as LFA-1 expressing Jurkat cells.

\section{Results and discussion}

Based on the three-dimensional structure, we predicted SARS-CoV protein 7 a to have a LFA-1 I domain binding activity (Hanel et al., 2006). To investigate this predicted function, we carried out various assays using LFA-1 expressing Jurkat cells, recombinant protein 7 a ectodomain and LFA-1 I domain wild type and mutant.

\section{Protein 7a binds preferably to activated Jurkat cells}

A remarkable feature of $\mathrm{T}$ lymphocyte interactions with other cells is the rapid progression from strong adhesion to de-adhesion. LFA-1, which is constitutively expressed on Jurkat cells (van Kooyk et al., 1993; Weber et al., 1997; Crucian et al., 2006), has been shown to exist in an active and inactive form. The active form can be induced artificially by stimuli, such as phorbolester (PMA, $\mathrm{PDBu}$ ) and antibodies, e.g., against CD3. In this process, phorbolesters induce the protein kinase $C$ to phosphorylate the $\beta$-subunit of LFA-1. This, in turn, induces conformational changes in LFA-1 with the consequence that LFA-1 favors binding with its ligand, e.g., ICAM-1 for cell adhesion. This increase in affinity to its ligand cannot be attributed to an increase of the LFA-1 expression level upon PDBu (phorbol-12,13-dibutyrate) activation. As was shown by numerous other studies, activation of $\mathrm{T}$ cells with phorbolester does not result in elevated expression levels of LFA-1 within a time period of even $2 \mathrm{~h}$ (Rothlein and Springer, 1986; Dustin and Springer, 1989; Lo et al., 1989; Kucik et al., 1996; Crucian et al., 2006).

ICAM-1 binds almost exclusively to LFA-1 I domain in its activated form (Dustin and Springer, 1989). To compare protein $7 \mathrm{a}$ binding to LFA-1 of activated and nonactivated Jurkat cells, the cells were activated nonspecifically by PDBu for $5 \mathrm{~min}, 20 \mathrm{~min}, 16 \mathrm{~h}$ or not at all, before $7 \mathrm{a}$ ectodomain was added to the cells. Non-activated Jurkat cells bound minor amounts of 7 a (Figure 1). After activation of the Jurkat cells, the amount of $7 \mathrm{a}$ bound to the cells was drastically increased. The level of $7 \mathrm{a}$ binding reached a maximum after $20 \mathrm{~min}$ and remained elevated for several hours. This experiment clearly shows that 7 a preferably binds to activated Jurkat cells. However, in contrast to ICAM-1, 7a also binds to non-activated Jurkat cells to a significantly reduced extent. ICAM binding to LFA-1 was also reported to reach its maximum after 20 min of PDBu activation (Dustin and Springer, 1989).

\section{Protein 7a binds to LFA-1 on the surface of PDBu- activated Jurkat cells}

To further investigate the potential LFA-1 binding activity of protein $7 \mathrm{a}$, activated Jurkat cells were incubated with varying concentrations of recombinant protein $7 \mathrm{a}$ ectodomain for $1 \mathrm{~h}$ at $4^{\circ} \mathrm{C}$. After washing, cell bound $7 \mathrm{a}$ was immunoprecipitated, subjected to sodium dodecyl sulfate-polyacrylamide gel electrophoresis (SDS-PAGE) and Western blotting (Figure 2A). Protein $7 a$ is detectable in a concentration-dependent manner and reached satu-

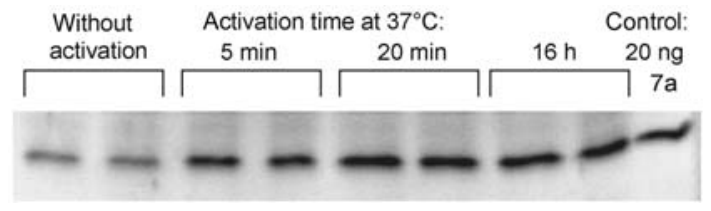

Figure 1 Effect of PDBu activation on protein $7 \mathrm{a}$ binding to Jurkat cells.

Jurkat cells $\left(2 \times 10^{6}\right)$ were activated with $50 \mathrm{~nm}$ PDBu for the indicated time periods. After incubation with $3.2 \mu \mathrm{M}$ (corresponds to $16 \mu \mathrm{g}$ in $500 \mu \mathrm{l}$ incubation volume) protein $7 \mathrm{a}$ for $1 \mathrm{~h}$, the cells were washed and the amount of cell-bound protein $7 \mathrm{a}$ was analyzed by Western blotting of the total cell protein after electrophoretic separation. As a positive control, $20 \mathrm{ng} 7 \mathrm{a}$ were applied to the rightmost lane. 
A

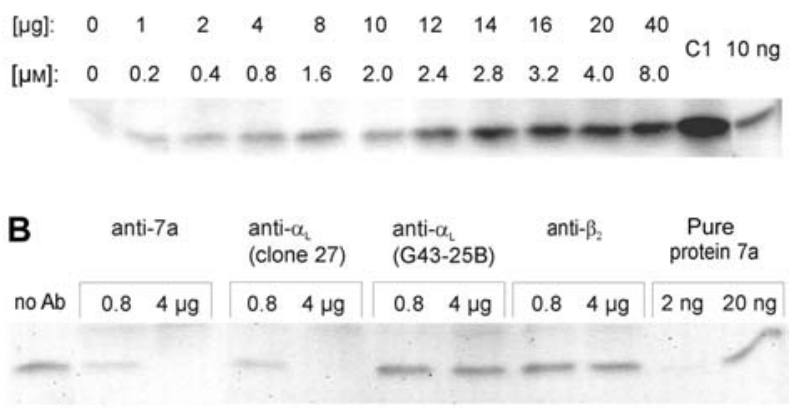

Figure 2 Binding of protein $7 a$ to the cell surface of activated Jurkat cells.

(A) $2 \times 10^{6}$ PDBu-activated Jurkat cells were incubated with the indicated amounts (between 0 and $40 \mu \mathrm{g}$ ) of 7 a protein in a total volume of $500 \mu \mathrm{l}$ (corresponding to $7 \mathrm{a}$ concentrations between 0 and $8 \mu \mathrm{M}$ ). After washing, the cells were lysed and centrifuged. Cell-bound protein 7a was immunoprecipitated with anti-7a antibody coupled to protein G Sepharose, washed, resuspended in $60 \mu \mathrm{l}$ Laemmli buffer and $10 \mu \mathrm{l}$ thereof were analyzed by Western blotting after electrophoretic separation. To verify that the binding capacity of anti-7a antibody loaded beads was not limiting in the experiment, $2 \mu \mathrm{g}$ of $7 \mathrm{a}$ was added to cell extract and applied to the anti-7a antibody loaded protein G Sepharose beads before SDS-PAGE analysis and subsequent Western blotting ('C1'). To estimate the amount of total 7 a protein on the Western blot, $10 \mathrm{ng}$ of purified protein $7 \mathrm{a}$ was applied directly to the SDS-PAGE and subsequent Western blotting as well (right lane). (B) $4 \times 10^{5}$ PDBu-activated Jurkat cells in a total volume of $100 \mu \mathrm{l}$ were incubated with $0.8 \mu \mathrm{g} 7 \mathrm{a}$ (corresponds to a concentration of $0.8 \mu \mathrm{M}$ ) without any antibody ('no Ab') or with 0.8 or $4.0 \mu \mathrm{g}$ (corresponds to concentrations of 0.06 or $0.3 \mu \mathrm{M}$, respectively) of various antibodies [anti-7a, anti- $\alpha_{L}$ (clone 27), anti- $\alpha_{L}$ (B43-25B), anti- $\beta_{2}$ ] for $1 \mathrm{~h}$. After washing, the cells were lysed and centrifuged. $7 \mathrm{a}$ protein in the supernatants was immunoprecipitated with anti-7a antibody coupled on protein G Sepharose, washed, resuspended in $50 \mu \mathrm{I}$ Laemmli buffer, and $20 \mu \mathrm{l}$ thereof analyzed with SDS-PAGE and subsequent Western blotting. To estimate the amount of total 7 a protein on the Western blot, $2 \mathrm{ng}$ and $20 \mathrm{ng}$ of purified protein 7 a were applied to the SDS-PAGE and subsequent Western blotting as well. It should be noted that the concentration of the anti-7a antibody in the experiment shown in lane 3 was $0.3 \mu \mathrm{M}$, which corresponds to $0.6 \mu \mathrm{M} 7 \mathrm{a}$ binding sites. This is a little less than 0.8 $\mu \mathrm{M} 7 \mathrm{a}$ protein employed in the assay. However, from lane 2 in panel $(\mathrm{A})$ it can be seen that the remaining $0.2 \mu \mathrm{M}$ 7a leads to a very low binding ratio, which obviously could not be detected to any further extent in the anti-7a binding competition experiment shown in lane 3.

ration at $7 \mathrm{a}$ concentrations above $3 \mu \mathrm{M}$, corresponding to $15 \mu \mathrm{g}$ in the assay. To verify that the observed saturation was not due to a limited binding capacity of the anti-7a antibody loaded beads used in the assay, $2 \mu \mathrm{g}$ of 7 a was directly applied to cell extract instead of living cells and subsequently immunoprecipitated with anti-7a antibody beads (control ' $\mathrm{C} 1$ ' in Figure 2A). This clearly shows that the observed saturation is due to a limited number of receptors on the Jurkat cells.

Although Western blotting is not the optimal method for the quantification of proteins, we intended to obtain an estimation of how many 7a molecules bound to one activated Jurkat cell. The right lane in the Western blot in Figure 2A represents $10 \mathrm{ng}$ of purified protein $7 \mathrm{a}$. An exact quantitative analysis was severely hindered due to strongly varying background signals in the different regions of the Western blot. Even though, we estimated the amount of 7 a protein obtained under saturation conditions to be approximately $150 \mathrm{ng}$, based on a densitometric analysis of the appropriate bands on the Western blot. If $2 \times 10^{6}$ PDBu-activated Jurkat cells are able to bind 7a protein in a 1:1 stoichiometry, this would mean $4 \times 10^{6}$ binding sites for 7 a protein per cell. T cell lines are reported to typically express between $1 \times 10^{5}$ and $1 \times 10^{6}$ LFA-1 molecules per cell (Sung et al., 1992). Thus, the number of binding sites for protein $7 a$ per Jurkat cell is in the range of that reported for LFA-1 on T cell lines.

As a control, the presence of close to half-equimolar polyclonal anti-7a antibodies virtually abolished 7a binding of Jurkat cells (Figure 2B). Taken together, these data show that $7 \mathrm{a}$ is bound by activated Jurkat cells and the number of binding sites is limited, suggesting that Jurkat cells carry a specific receptor for $7 a$.

\section{The 7a binding site on Jurkat cells is the $\alpha_{\mathrm{L}}$ subunit of LFA-1}

Binding of $7 a$ to Jurkat cells was inhibited in presence of a monoclonal anti-CD11a antibody 'clone 27' raised against residues $64-199$ of the $\alpha_{\mathrm{L}}$-subunit of LFA-1 (Figure $2 \mathrm{~B}$ ). Therefore, although the exact epitope of antibody anti-CD11a (clone 27) is not known, it can be expected to be either within the I domain or close to the I domain. A monoclonal antibody increased against the $\beta_{2}$-subunit did not interfere with 7a binding. Another antibody (clone G43-25B) directed against the $\alpha_{\mathrm{L}}$-subunit of LFA-1 did not interfere with $7 \mathrm{a}$ binding either. The exact epitope of antibody G43-25B is not known. However, G43-25B is known not to block the ICAM-1/LFA-1 interaction (Mizuno et al., 1997). This is in perfect agreement with the prediction that $7 \mathrm{a}$ binds to the same LFA-1 site as ICAM-1 does, which is the I domain of the $\alpha_{\mathrm{L}}$ subunit.

\section{Direct in vitro binding of $7 a$ to wild type and mutant I domain}

Recombinant wild type I domain of LFA-1 is known to represent the non-activated conformation. This so-called 'closed' state of LFA-1 exerts low affinity to ICAM-1. A mutant I domain was described that mimics the active conformation having a 10000 -fold increased affinity for ICAM-1 (Shimaoka et al., 2003).

To clearly identify the I domain of LFA-1 to be the $7 \mathrm{a}$ binding site, and to further investigate $7 a$ binding to activated and non-activated I domain in a semi-quantitative way, wild type, as well as mutant I domain, were coated in wells of a microtiter plate and incubated with increasing concentrations of protein 7a. After thorough washing, the amount of 7 a protein that was still bound to wild type or mutant I domain was determined by an ELISA employing anti-7a antibody and horseradish peroxidase (HRP) coupled anti-rabbit antibody as primary and secondary antibodies, respectively.

Wild type I domain bound $7 \mathrm{a}$ with a virtually linear concentration dependence. Up to $20 \mu \mathrm{M} 7 \mathrm{a}$, no saturation effect could be observed. Mutant I domain, as well, bound $7 \mathrm{a}$ in a strong concentration-dependent manner, 
but in contrast to wild type mutant I domain binding to protein 7 a reached saturation at 7 a concentrations above $5 \mu \mathrm{M}$. This clearly shows that $7 \mathrm{a}$ binds significantly tighter to mutant I domain as compared to wild type I domain (Figure 3). This is in full accordance with the $7 a$ binding characteristic observed with activated and nonactivated Jurkat cells. Binding of 7 a to mutant I domain reached its half maximum at approximately $3 \mu \mathrm{M}$ concentration (Figure 3). This is in good accordance to the half maximum of $7 \mathrm{a}$ binding to activated Jurkat cells at approximately $2.4 \mu \mathrm{M}$ (Figure $2 \mathrm{~A}$ ). A thereby derived $K_{\mathrm{d}}$ value for $7 \mathrm{a}$ binding to mutant I domain in the very low $\mu \mathrm{M}$ range compares well with the reported $K_{\mathrm{d}}$ value of $0.4 \mu \mathrm{M}$ for the affinities of soluble ICAM-1 to activated LFA-1 expressing T cells (Lollo et al., 1993). The same report assigns ICAM binding to non-activated T cells with a $K_{\mathrm{d}}$ value of $100 \mu \mathrm{m}$.

Interestingly, the K287C/K294C mutant I domain was constructed to mimic the conformation with the highest affinity to ICAM-1. The prediction that 7 a shows similar binding behavior as ICAM-1 implicates that $7 \mathrm{a}$, too, binds more tightly to mutant I domain as compared to wild type I domain. This is exactly what was found in the ELISA (Figure 3). This underlines the similarities of the I domain binding surfaces of $7 \mathrm{a}$ and ICAM-1, exactly as predicted previously by us (Hanel et al., 2006).

An essential feature of the ICAM-1 LFA-1 interaction is its metal ion-dependency (Dustin and Springer, 1989; Shimaoka et al., 2001). Neither the ELISA, nor the Jurkat cell binding assays were suitable to investigate the metal ion-dependence of $7 \mathrm{a}$ binding to wild type or mutant I domain (data not shown).

\section{Potential biological implications of $7 \mathrm{a}$ interaction with LFA-1}

The main target cells of SARS-CoV are bronchial epithelium cells, type I and II pneumocytes, T lymphocytes and macrophages/monocytes (Ye et al., 2007). The clinical picture is characterized by a cascade of immunological

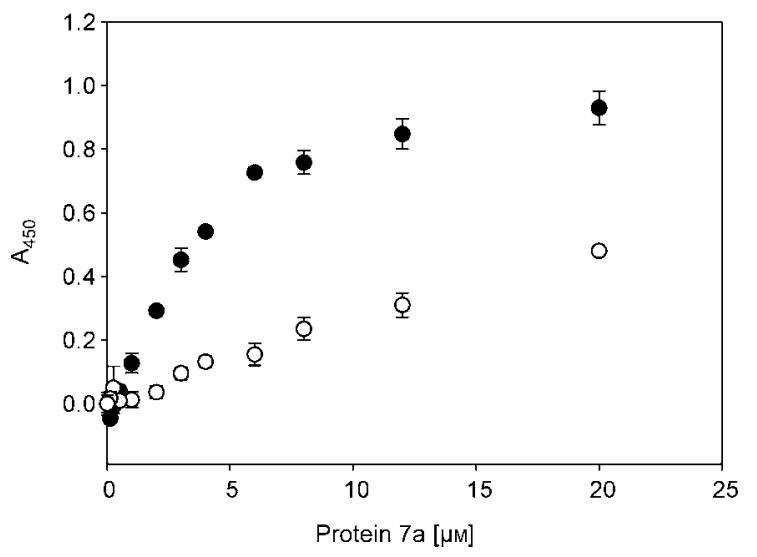

Figure 3 Protein 7a ELISA with wild type and mutant I domain. Microtiter plates were coated with $0.5 \mu \mathrm{M}$ of either wild type (open circles) or mutant (K287C/K294C, closed circles) I domain in $100 \mu \mathrm{l}$. After washing, $100 \mu \mathrm{l}$ of the indicated concentrations of protein 7 a were added, incubated, washed and remaining 7 a was quantified by ELISA (as described). Each symbol in the diagram represents the mean of three experiments with the respective standard deviations indicated as vertical bars. events leading to pulmonary inflammation and respiratory failure (Hsiao et al., 2004; Openshaw, 2004). High levels of cytokines and chemokines triggered by the host immune response to SARS-CoV are believed to contribute to the progressive pulmonary infiltration of macrophages (Nicholls et al., 2003), neutrophiles and T cells (Jiang et al., 2005; Yen et al., 2006).

So far, the angiotensin-converting enzyme 2 (ACE2) ( $\mathrm{Li}$ et al., 2003b) has been identified as the major receptor for SARS-CoV. ACE2 is expressed in various tissues, but mainly in endothelial cells including lung alveolar epithelial cells, enterocytes of the small intestine and arterial and venous endothelial cells (Harmer et al., 2002; Hamming et al., 2004). Cathepsin $L$ is discussed to play a role in the viral infection process (Chan et al., 2004; Huang et al., 2006b; Ye et al., 2007). DC-SIGNR (L-SIGN, CD209L) and DC-SIGN (CD209) have been shown to enhance infection of ACE2-expressing cells (Jeffers et al., 2004; Marzi et al., 2004; Yang et al., 2005), but are not able to mediate efficient infection in the absence of ACE2 (Jeffers et al., 2004; Marzi et al., 2004). Expression of DC-SIGN is largely restricted to dendritic cells (Geijtenbeek et al., 2000) and alveolar macrophages (Soilleux et al., 2002). DC-SIGNR is expressed in lymph node and liver sinusoidal endothelial cells (Pohlmann et al., 2001).

In summary, all these findings suggest that receptors or cofactors not yet identified may be involved in the interaction between the virus and target cells. This is especially true for cell types that are reported to be infected by SARS-CoV, but do not express ACE2, e.g., T lymphocytes (Harmer et al., 2002; Hamming et al., 2004; Jiang et al., 2005). LFA-1 is exclusively expressed on the surface of leukocytes. It mediates several adhesive interactions among cells of the immune system. Furthermore, LFA-1 mediates interactions of leukocytes with the endothelium and transendothelial migration of leukocytes (Bleijs et al., 2001; Ye et al., 2007). The consequences of the hereby-characterized LFA-1 binding activity of $7 \mathrm{a}$ depend largely on the subcellular localization of $7 a$ in infected cells or virus particles.

The presence of LFA-1 binding $7 \mathrm{a}$ molecules on the virus surface would allow the virus to use LFA-1 as an attachment factor or a receptor for cell entry. An interesting example is known from HIV-1, of which virus particles were found bearing incorporated host-encoded ICAM-1 on their surface. This led to a 5- to 10-fold increase in infectivity, caused by an interaction between virally incorporated ICAM-1 and cell surface LFA-1 (Fortin et al., 1997). Indeed, 7a was recently reported to be localized on the virus surface (Huang et al., 2006a), and although it was shown that SARS-CoV does not infect $T$ cell lines in vitro (Hattermann et al., 2005), SARS-CoV is reported to infect $\mathrm{T}$ cells and macrophages ( $\mathrm{Li}$ et al., 2003a; Gu et al., 2005; Yen et al., 2006; Ye et al., 2007). Thus, our observation that LFA-1 is a ligand of 7 a could possibly suggest that LFA-1 is the SARS-CoV receptor in T cells. Alternatively, LFA-1 may act as an attachment factor for SARS-CoV that contributes to increased virus attachment to $\mathrm{T}$ cells.

Protein 7 a was already described to be primarily located in the ER of infected cells and to contain an ER retention signal (Fielding et al., 2004). An interaction of 7 a with 
newly synthesized LFA-1 molecules in the ER could prevent LFA-1 delivery to the cell surface and consequently take influence on LFA-1 mediated functions. Prominent examples of viral accessory proteins with such functions are known from other viruses, e.g., HIV-1 Vpu binds to CD4 and prevents CD4 delivery to the cell surface and even induces its degradation (Schubert and Strebel, 1994; Schubert et al., 1998).

The presence of $7 \mathrm{a}$ on the virus surface (Huang et al., 2006a) and all the data shown in the present study strongly suggest LFA-1 to be a viral attachment factor or even the SARS-CoV receptor of human leucocytes. Further, protein 7a should also be able to downregulate surface LFA-1 expression by inhibiting its delivery from the ER to the cell surface to decrease the risk of superinfection of already infected cells. Post-infective downregulation of viral receptors is a common feature of viral strategies. A prominent example is CD4 downregulation by HIV-1 proteins, Nef and Vpu.

\section{Materials and methods}

\section{Cells and antibodies}

Jurkat cells (DSMZ, ACC 282) were cultured in suspension in RPMI 1640 medium, 2 mM L-glutamine supplemented with 10\% FCS (fetal calf serum; Biochrom AG, Berlin, Germany) and 50 $\mu \mathrm{g} / \mathrm{ml}$ gentamycin under $5 \% \mathrm{CO}_{2}$.

Anti-CD11a (clone 27), anti-CD11a (clone G43-25B, nonblocking for ICAM-1/LFA-1 interaction) and anti-CD18 (clone 6.7) mAbs were purchased from BD Pharmingen (San Diego, CA, USA). The secondary anti-rabbit mAb for Western blotting was purchased from Pierce (Rockford, IL, USA).

To obtain an antibody against SARS-CoV 7 a protein, purified $7 a$ ectodomain in native form was used for rabbit immunization (Eurogentec, Seraing, Belgium). The derived serum was used for immunoprecipitation experiments and Western blot analysis. For some experiments, anti-7a antibodies were purified using a $7 \mathrm{a}$ ectodomain to NHS-activated sepharose 4 fast flow (GE Healthcare, Munich, Germany). The specificity of protein $7 a$ antibody was tested by ELISA. Pre-immune serum and serum of the final bleeding were tested in different dilutions (between 1:5000 and 1:40 000) against protein $7 a$ or bovine serum albumin (BSA, as a control) coated on plastic. A positive signal was obtained only with serum from the final bleeding and protein $7 \mathrm{a}$-coated wells.

\section{Cloning and purification of recombinant protein $7 \mathrm{a}$ ectodomain and LFA-1 I domains}

SARS-CoV protein 7 a ectodomain was expressed and purified as described earlier (Hanel et al., 2006). To obtain wild type LFA1 I domain, clone IRALp962H144Q (RZPD) was used as template for PCR. The CDNA of LFA-1 showed a deletion in the 5'-region of the I domain. Synthetic primers (5'-GGA AAA CTG AAC AGC AGC AAA CTG GTA CGA AGT GTT GCT GAG TाT CTT CAT CAC ATC CTT CAT GAA GTC CAG AAT TIT CTG AAA TTC ATC-3', and 5'-GGA ATT CCA TAT GGT AGA CCT GGT ATT TCT GTT TGA TGG TTC GAT GAG CTT GCA GCC AGA TGA ATT TCA GAA AAT TCT GG-3') were used to generate a PCR amplificate coding for the amino-terminus of I domain.

The amplificate was used as forward primer to amplify the DNA that codes the I domain with the RZPD clone as template, and 5'-CTG AGC TGC AGA AGA AGA TCT AAC GGG ATC CCG$3^{\prime}$ as the reverse primer. Restriction sites, Ndel and BamHI, were used to insert the DNA into the multiple cloning site (MCS) of
pET43b yielding the plasmid pID-wt DNA coding the $\alpha_{\mathrm{L}}$ highaffinity mutant K287C/K294C (Shimaoka et al., 2003) and was obtained by polymerase chain reaction (PCR) using the primers 5'-GGA ATT CCA TAT GGT AGA CCT GGT ATT TC-3', and 5'-CGG GAT CCC GTT AGA TCT TCT TCT GGA GCT CAG TGA ATA GAT CTT TCA GGC ACT CAA ATG TGT CCA GAA TGC ACA CAA ACT CGC TCG C-3'. Again, restriction sites, Ndel and BamHI, were used to insert the DNA into the MCS of pET43b yielding the plasmid pID-mut. DNA sequences were confirmed by DNA sequencing. For expression of wild type and K287C/ K294C mutant I domain, plasmids pID-wt and pID-mut were transformed into BL21(DE3). Protein expression and purification was carried out as described previously (Legge et al., 2000) with minor modifications. Escherichia coli cells from 1 I expression culture were pelleted, resuspended in $30 \mathrm{ml}$ buffer $\mathrm{A}$ [50 mM Tris- $\mathrm{HCl}, 2 \mathrm{~mm}$ dithiothreitol (DTT) and $2 \mathrm{~mm}$ EDTA pH 8] and lysed by sonification. After centrifugation at $15000 \mathrm{~g}$ for $30 \mathrm{~min}$, the supernatant was discarded and the pellet resuspended again in buffer $A$. This procedure was repeated 5-7 times to purify inclusion bodies. The inclusion bodies were solubilized in buffer B (6 M guanidinium hydrochloride, $50 \mathrm{~mm}$ Tris- $\mathrm{HCl}$ and 20 $\mathrm{mM}$ DTT $\mathrm{pH}$ 8) for $2 \mathrm{~h}$ and centrifuged at $15000 \mathrm{~g}$ for $30 \mathrm{~min}$. The protein concentration was adjusted to $1 \mathrm{mg} / \mathrm{ml}$. For renaturation, the wild type I domain was rapidly diluted to $50 \mu \mathrm{g} / \mathrm{ml}$ in buffer C $\left(50 \mathrm{~mm}\right.$ Tris- $\mathrm{HCl}$ pH 8.5, $1 \mathrm{~mm}$ DTT, 1 mM $\mathrm{MgSO}_{4}$ and $5 \%$ glycerol) and stirred overnight at $4{ }^{\circ} \mathrm{C}$. Mutant I domain was refolded with buffer not containing DTT to allow formation of disulfide bridges. To remove denaturated protein the solution was filtrated, concentrated and loaded onto a Q-Sepharose column equilibrated in buffer $C$. Elution was performed with a $0-1-\mathrm{M} \mathrm{NaCl}$ gradient in buffer $\mathrm{C}$. Wild type I domain eluted between 50 and $100 \mathrm{~mm} \mathrm{NaCl}$, the mutant I domain at $120 \mathrm{mM}$ $\mathrm{NaCl}$.

Successful refolding of wild type I domain WT was confirmed by NMR spectroscopy. The ${ }^{1} \mathrm{H}^{15} \mathrm{~N}-\mathrm{HSQC}$ spectrum of ${ }^{15} \mathrm{~N}-$ labeled protein was identical to the ${ }^{1} \mathrm{H}{ }^{15} \mathrm{~N}-\mathrm{HSQC}$ spectrum reported previously (Legge et al., 2000). In the case of the mutant I domain, the one-dimensional proton NMR spectrum was compared with the proton spectrum of wild type I domain. After reduction of the disulfide bridges in the presence of $\beta$-mercaptoethanol, both proton spectra were virtually identical (data not shown).

\section{Jurkat cell surface binding of $7 a$}

Jurkat cells were activated with $50 \mathrm{~nm}$ PDBu (phorbol-12, 13dibutyrate; Sigma, Munich, Germany) at $37^{\circ} \mathrm{C}$ for $20 \mathrm{~min}$ in RPMI 1640 medium supplemented with $5 \% \mathrm{FCS}, 2 \mathrm{mM} \mathrm{CaCl}_{2}$ and 2 $\mathrm{mM} \mathrm{MgCl}_{2}$. Cells $\left(500 \mu \mathrm{l}\right.$; approximately $2 \times 10^{6}$ cells per tube) were immediately cooled on ice, incubated with varying (0.2-8 $\mu \mathrm{M})$ concentrations of protein $7 \mathrm{a}$ for $1 \mathrm{~h}$ at $4^{\circ} \mathrm{C}$. To remove unbound protein, the cells were washed three times with icecold phosphate-buffered saline (PBS) and subsequently lysed in $500 \mu \mathrm{l}$ lysis buffer [PBS with $1 \mathrm{~mm} \mathrm{MgCl}, 5 \mathrm{~mm}$ octylthioglucosid (Sigma) and Complete Mini EDTA-free (Roche, Mannheim, Germany) Anti-Protease Mixture] for $30 \mathrm{~min}$ at $4^{\circ} \mathrm{C}$. After centrifugation with $20000 \mathrm{~g}$ at $4^{\circ} \mathrm{C}$, the supernatant was incubated for $1 \mathrm{~h}$ at $4^{\circ} \mathrm{C}$ with anti-7a antibody coated protein $\mathrm{G}$ sepharose beads (Amersham, Freiburg, Germany). The beads were washed three times with lysis buffer and then resuspended in Laemmli buffer and subjected to SDS-PAGE and Western blotting.

\section{Western blotting}

Sample aliquots were electrophoresed and transferred onto Immobilon-Pos membranes (Millipore, Schwalbach, Germany) using a semi-dry transfer unit (Hoefer, Munich, Germany) at room temperature for $15 \mathrm{~min}$. The membrane was blocked with 
BSA containing TBST (Tris-buffered saline containing $0.1 \%$ Tween 20) for $1 \mathrm{~h}$ at room temperature and subsequently incubated with anti-protein 7 a serum for $24 \mathrm{~h}$ at $4^{\circ} \mathrm{C}$. After washing the membrane three times with TBST buffer, the membrane was incubated with the HRP-coupled secondary anti-rabbit mAb for $24 \mathrm{~h}$ at $4^{\circ} \mathrm{C}$. After washing another three times with TBST, the membrane was incubated with SuperSignal west pico substrate (Pierce) according to manufacturer's recommendations for visualization of the bands with GelDoc 2000 System (Bio-Rad, Munich, Germany). For densitometric analysis, we used the program 'quantity one' version 4.4.0 (Bio-Rad).

\section{ELISA}

Solid-phase binding assays were carried out on 96 well plates coated with $100 \mu \mathrm{l}$ of $0.5 \mu \mathrm{M}$ wild type or mutant I domain in Tris-HCl-Mg-buffer (20 mM Tris- $\mathrm{HCl}, \mathrm{pH} 7,1 \mathrm{~mm} \mathrm{MgCl}$ ) overnight at $4^{\circ} \mathrm{C}$. Non-specific binding was blocked with $5 \mathrm{mg} / \mathrm{ml}$ BSA $1 \mathrm{~h}$ at room temperature. The plates were washed three times with $300 \mu \mathrm{l}$ Tris-HCl-Mg-buffer containing 0.1\% Tween 20 . Purified protein $7 \mathrm{a}$ was then added at concentrations from 0.125 $\mu \mathrm{M}$ to $20 \mu \mathrm{M}$ in $100 \mu \mathrm{l}$ Tris-HCl-Mg-buffer for $1 \mathrm{~h}$ at room temperature. After washing, the plates were incubated with anti-protein 7a serum diluted 1:15 000 in Tris-HCl-Mg-buffer containing $0.1 \%$ Tween 20. After $1 \mathrm{~h}$ at room temperature, the microtiter plates were washed, and HRP-conjugated anti-rabbit antibody (diluted 1:10 000) was added in Tris-HCl-Mg-buffer with $0.1 \%$ Tween 20 for $1 \mathrm{~h}$ at room temperature. After washing, $100 \mu \mathrm{l}$ of a developing solution containing TMB (tetramethylbenzidine, Sigma) was added and incubated for $10 \mathrm{~min}$ at room temperature. The reaction was stopped with $100 \mu \mathrm{l}$ of $2 \mathrm{M}$ sulfuric acid and absorbance was measured at $450 \mathrm{~nm}$. All values were obtained in triplicate and specific absorbance calculated by subtracting non-specific absorbance (in the absence of protein 7a) from total absorbance.

\section{References}

Blatch, G.L. and Lassle, M. (1999). The tetratricopeptide repeat: a structural motif mediating protein-protein interactions. Bioessays 21, 932-939.

Bleijs, D.A., Geijtenbeek, T.B., Figdor, C.G., and van Kooyk, Y. (2001). DC-SIGN and LFA-1: a battle for ligand. Trends Immunol. 22, 457-463.

Chan, P.K., To, K.F., Lo, A.W., Cheung, J.L., Chu, I., Au, F.W., Tong, J.H., Tam, J.S., Sung, J.J., and Ng, H.K. (2004). Persistent infection of SARS coronavirus in colonic cells in vitro. J. Med. Virol. 74, 1-7.

Chen, Y.Y., Shuang, B., Tan, Y.X., Meng, M.J., Han, P., Mo, X.N., Song, Q.S., Quu, X.Y., Luo, X., Gan, Q.N., et al. (2005). The protein $\mathrm{X} 4$ of severe acute respiratory syndrome-associated coronavirus is expressed on both virus-infected cells and lung tissue of severe acute respiratory syndrome patients and inhibits growth of Balb/c 3T3 cell line. Chin. Med. J. (Engl.) 118, 267-274.

Crucian, B., Nelman-Gonzalez, M., and Sams, C. (2006). Rapid flow cytometry method for quantitation of LFA-1-adhesive T cells. Clin. Vaccine Immunol. 13, 403-408.

de Haan, C.A., Volders, H., Koetzner, C.A., Masters, P.S., and Rottier, P.J. (2002). Coronaviruses maintain viability despite dramatic rearrangements of the strictly conserved genome organization. J. Virol. 76, 12491-12502.

Dustin, M.L. and Springer, T.A. (1989). T-cell receptor cross-linking transiently stimulates adhesiveness through LFA- 1 . Nature 341, 619-624.
Fielding, B.C., Tan, Y.J., Shuo, S., Tan, T.H., Ooi, E.E., Lim, S.G., Hong, W., and Goh, P.Y. (2004). Characterization of a unique group-specific protein (U122) of the severe acute respiratory syndrome coronavirus. J. Virol. 78, 7311-7318.

Fielding, B.C., Gunalan, V., Tan, T.H., Chou, C.F., Shen, S., Khan, S., Lim, S.G., Hong, W., and Tan, Y.J. (2006). Severe acute respiratory syndrome coronavirus protein $7 \mathrm{a}$ interacts with hSGT. Biochem. Biophys. Res. Commun. 343, 1201-1208.

Fortin, J.F., Cantin, R., Lamontagne, G., and Tremblay, M. (1997). Host-derived ICAM-1 glycoproteins incorporated on human immunodeficiency virus type 1 are biologically active and enhance viral infectivity. J. Virol. 71, 3588-3596.

Geijtenbeek, T.B., Torensma, R., van Vliet, S.J., van Duijnhoven, G.C., Adema, G.J., van Kooyk, Y., and Figdor, C.G. (2000). Identification of DC-SIGN, a novel dendritic cell-specific ICAM-3 receptor that supports primary immune responses. Cell 100, 575-585.

Gu, J., Gong, E., Zhang, B., Zheng, J., Gao, Z., Zhong, Y., Zou, W., Zhan, J., Wang, S., Xie, Z., et al. (2005). Multiple organ infection and the pathogenesis of SARS. J. Exp. Med. 202, 415-424.

Haijema, B.J., Volders, H., and Rottier, P.J. (2004). Live, attenuated coronavirus vaccines through the directed deletion of group-specific genes provide protection against feline infectious peritonitis. J. Virol. 78, 3863-3871.

Hamming, I., Timens, W., Bulthuis, M.L., Lely, A.T., Navis, G.J., and van Goor, H. (2004). Tissue distribution of ACE2 protein, the functional receptor for SARS coronavirus. A first step in understanding SARS pathogenesis. J. Pathol. 203, 631-637.

Hanel, K., Stangler, T., Stoldt, M., and Willbold, D. (2006). Solution structure of the $\mathrm{X} 4$ protein coded by the SARS related coronavirus reveals an immunoglobulin like fold and suggests a binding activity to integrin I domains. J. Biomed. Sci. 13, 281-293.

Harmer, D., Gilbert, M., Borman, R., and Clark, K.L. (2002). Quantitative mRNA expression profiling of ACE 2, a novel homologue of angiotensin converting enzyme. FEBS Lett. 532, 107-110.

Hattermann, K., Muller, M.A., Nitsche, A., Wendt, S., Donoso Mantke, O., and Niedrig, M. (2005). Susceptibility of different eukaryotic cell lines to SARS-coronavirus. Arch. Virol. 150, 1023-1031.

Hsiao, C.H., Wu, M.Z., Hsieh, S.W., Chien, L.C., Hwang, K.C., and Su, I.J. (2004). Clinicopathology of severe acute respiratory syndrome: an autopsy case report. J. Formos Med. Assoc. 103, 787-792.

Huang, C., Ito, N., Tseng, C.T., and Makino, S. (2006a). Severe acute respiratory syndrome coronavirus 7 a accessory protein is a viral structural protein. J. Virol. 80, 7287-7294.

Huang, I.C., Bosch, B.J., Li, F., Li, W., Lee, K.H., Ghiran, S., Vasilieva, N., Dermody, T.S., Harrison, S.C., Dormitzer, P.R., et al. (2006b). SARS coronavirus, but not human coronavirus NL63, utilizes cathepsin L to infect ACE2-expressing cells. J. Biol. Chem. 281, 3198-3203.

Hynes, R.O. (2002). Integrins: bidirectional, allosteric signaling machines. Cell 110, 673-687.

Jeffers, S.A., Tusell, S.M., Gillim-Ross, L., Hemmila, E.M., Achenbach, J.E., Babcock, G.J., Thomas, W.D. Jr., Thackray, L.B., Young, M.D., Mason, R.J., et al. (2004). CD209L (LSIGN) is a receptor for severe acute respiratory syndrome coronavirus. Proc. Natl. Acad. Sci. USA 101, 15748-15753.

Jiang, Y., Xu, J., Zhou, C., Wu, Z., Zhong, S., Liu, J., Luo, W., Chen, T., Qin, Q., and Deng, P. (2005). Characterization of cytokine/chemokine profiles of severe acute respiratory syndrome. Am. J. Respir. Crit. Care Med. 171, 850-857.

Kanzawa, N., Nishigaki, K., Hayashi, T., Ishii, Y., Furukawa, S., Niiro, A., Yasui, F., Kohara, M., Morita, K., Matsushima, K., et al. (2006). Augmentation of chemokine production by severe acute respiratory syndrome coronavirus $3 a / X 1$ and $7 \mathrm{a} / \mathrm{X} 4$ proteins through NF-kB activation. FEBS Lett. 580 , 6807-6812. 
Kinashi, T. (2006). Adhere upright: a switchblade-like extension of $\beta 2$ integrins. Immunity 25, 521-522.

Kopecky-Bromberg, S.A., Martinez-Sobrido, L., and Palese, P. (2006). 7a protein of severe acute respiratory syndrome coronavirus inhibits cellular protein synthesis and activates p38 mitogen-activated protein kinase. J. Virol. 80, 785-793.

Kucik, D.F., Dustin, M.L., Miller, J.M., and Brown, E.J. (1996). Adhesion-activating phorbol ester increases the mobility of leukocyte integrin LFA-1 in cultured lymphocytes. J. Clin. Invest. 97, 2139-2144.

Legge, G.B., Kriwacki, R.W., Chung, J., Hommel, U., Ramage, P., Case, D.A., Dyson, H.J., and Wright, P.E. (2000). NMR solution structure of the inserted domain of human leukocyte function associated antigen-1. J. Mol. Biol. 295, 1251-1264.

Li, L., Wo, J., Shao, J., Zhu, H., Wu, N., Li, M., Yao, H., Hu, M., and Dennin, R.H. (2003a). SARS-coronavirus replicates in mononuclear cells of peripheral blood (PBMCs) from SARS patients. J. Clin. Virol. 28, 239-244.

Li, W., Moore, M.J., Vasilieva, N., Sui, J., Wong, S.K., Berne, M.A., Somasundaran, M., Sullivan, J.L., Luzuriaga, K., Greenough, T.C., et al. (2003b). Angiotensin-converting enzyme 2 is a functional receptor for the SARS coronavirus. Nature 426, 450-454.

Lo, S.K., Detmers, P.A., Levin, S.M., and Wright, S.D. (1989). Transient adhesion of neutrophils to endothelium. J. Exp. Med. 169, 1779-1793.

Lollo, B.A., Chan, K.W., Hanson, E.M., Moy, V.T., and Brian, A.A. (1993). Direct evidence for two affinity states for lymphocyte function-associated antigen 1 on activated T cells. J. Biol. Chem. 268, 21693-21700.

Marra, M.A., Jones, S.J., Astell, C.R., Holt, R.A., Brooks-Wilson, A., Butterfield, Y.S., Khattra, J., Asano, J.K., Barber, S.A., Chan, S.Y., et al. (2003). The Genome sequence of the SARSassociated coronavirus. Science 300, 1399-1404.

Marzi, A., Gramberg, T., Simmons, G., Moller, P., Rennekamp, A.J., Krumbiegel, M., Geier, M., Eisemann, J., Turza, N., Saunier, B., et al. (2004). DC-SIGN and DC-SIGNR interact with the glycoprotein of Marburg virus and the $S$ protein of severe acute respiratory syndrome coronavirus. J. Virol. 78, 1209012095.

Mizuno, T., Yoshihara, Y., Inazawa, J., Kagamiyama, H., and Mori, K. (1997). cDNA cloning and chromosomal localization of the human telencephalin and its distinctive interaction with lymphocyte function-associated antigen-1. J. Biol. Chem. 272, 1156-1163.

Nelson, C.A., Pekosz, A., Lee, C.A., Diamond, M.S., and Fremont, D.H. (2005). Structure and intracellular targeting of the SARS-coronavirus Orf7a accessory protein. Structure 13, 75-85.

Nicholls, J.M., Poon, L.L., Lee, K.C., Ng, W.F., Lai, S.T., Leung, C.Y., Chu, C.M., Hui, P.K., Mak, K.L., Lim, W., et al. (2003). Lung pathology of fatal severe acute respiratory syndrome. Lancet 361, 1773-1778.

Nishida, N., Xie, C., Shimaoka, M., Cheng, Y., Walz, T., and Springer, T.A. (2006). Activation of leukocyte $\beta 2$ integrins by conversion from bent to extended conformations. Immunity 25, 583-594.

Openshaw, P.J. (2004). What does the peripheral blood tell you in SARS? Clin. Exp. Immunol. 136, 11-12.

Ortego, J., Sola, I., Almazan, F., Ceriani, J.E., Riquelme, C., Balasch, M., Plana, J., and Enjuanes, L. (2003). Transmissible gastroenteritis coronavirus gene 7 is not essential but influences in vivo virus replication and virulence. Virology 308 , 13-22.

Pohlmann, S., Soilleux, E.J., Baribaud, F., Leslie, G.J., Morris, L.S., Trowsdale, J., Lee, B., Coleman, N., and Doms, R.W. (2001). DC-SIGNR, a DC-SIGN homologue expressed in endothelial cells, binds to human and simian immunodeficiency viruses and activates infection in trans. Proc. Natl. Acad. Sci. USA 98, 2670-2675.
Rota, P.A., Oberste, M.S., Monroe, S.S., Nix, W.A., Campagnoli, R., Icenogle, J.P., Penaranda, S., Bankamp, B., Maher, K., Chen, M.H., et al. (2003). Characterization of a novel coronavirus associated with severe acute respiratory syndrome. Science 300, 1394-1399.

Rothlein, R. and Springer, T.A. (1986). The requirement for lymphocyte function-associated antigen 1 in homotypic leukocyte adhesion stimulated by phorbol ester. J. Exp. Med. 163, 1132-1149.

Schubert, U. and Strebel, K. (1994). Differential activities of the human immunodeficiency virus type 1-encoded Vpu protein are regulated by phosphorylation and occur in different cellular compartments. J. Virol. 68, 2260-2271.

Schubert, U., Antón, L.C., Bacík, I., Cox, J.H., Bour, S., Bennink, J.R., Orlowski, M., Strebel, K., and Yewdell, J.W. (1998). CD4 glycoprotein degradation induced by human immunodeficiency virus type $1 \mathrm{Vpu}$ protein requires the function of proteasomes and the ubiquitin-conjugating pathway. J. Virol. 72, 2280-2288.

Shimaoka, M., Lu, C., Palframan, R.T., von Andrian, U.H., McCormack, A., Takagi, J., and Springer, T.A. (2001). Reversibly locking a protein fold in an active conformation with a disulfide bond: integrin $\alpha \mathrm{L}$ I domains with high affinity and antagonist activity in vivo. Proc. Natl. Acad. Sci. USA 98, 6009-6014.

Shimaoka, M., Xiao, T., Liu, J.H., Yang, Y., Dong, Y., Jun, C.D., McCormack, A., Zhang, R., Joachimiak, A., Takagi, J., et al. (2003). Structures of the $\alpha \mathrm{L} I$ domain and its complex with ICAM-1 reveal a shape-shifting pathway for integrin regulation. Cell 112, 99-111.

Soilleux, E.J., Morris, L.S., Leslie, G., Chehimi, J., Luo, Q., Levroney, E., Trowsdale, J., Montaner, L.J., Doms, R.W., Weissman, D., et al. (2002). Constitutive and induced expression of DC-SIGN on dendritic cell and macrophage subpopulations in situ and in vitro. J. Leukoc. Biol. 71, 445-457.

Sung, K.L., Kuhlman, P., Maldonado, F., Lollo, B.A., Chien, S., and Brian, A.A. (1992). Force contribution of the LFA-1/ ICAM-1 complex to T cell adhesion. J. Cell. Sci. 103, 259-266.

Tan, Y.J., Fielding, B.C., Goh, P.Y., Shen, S., Tan, T.H., Lim, S.G., and Hong, W. (2004a). Overexpression of 7a, a protein specifically encoded by the severe acute respiratory syndrome coronavirus, induces apoptosis via a caspase-dependent pathway. J. Virol. 78, 14043-14047.

Tan, Y.J., Teng, E., Shen, S., Tan, T.H., Goh, P.Y., Fielding, B.C., Ooi, E.E., Tan, H.C., Lim, S.G., and Hong, W. (2004b). A novel severe acute respiratory syndrome coronavirus protein, U274, is transported to the cell surface and undergoes endocytosis. J. Virol. 78, 6723-6734.

van Kooyk, Y., van de Wiel-van Kemenade, E., Weder, P., Huijbens, R.J., and Figdor, C.G. (1993). Lymphocyte functionassociated antigen 1 dominates very late antigen 4 in binding of activated $\mathrm{T}$ cells to endothelium. J. Exp. Med. 177, 185-190.

Weber, K.S., York, M.R., Springer, T.A., and Klickstein, L.B. (1997). Characterization of lymphocyte function-associated antigen 1 (LFA-1)-deficient $T$ cell lines: the $\alpha \mathrm{L}$ and $\beta 2$ subunits are interdependent for cell surface expression. J. Immunol. 158, 273-279.

Yang, Y., Xiong, Z., Zhang, S., Yan, Y., Nguyen, J., Ng, B., Lu, H., Brendese, J., Yang, F., Wang, H., et al. (2005). Bcl-xL inhibits T-cell apoptosis induced by expression of SARS coronavirus $\mathrm{E}$ protein in the absence of growth factors. Biochem. J. 392, 135-143.

Ye, J., Zhang, B., Xu, J., Chang, Q., McNutt, M.A., Korteweg, C., Gong, E., and Gu, J. (2007). Molecular pathology in the lungs of severe acute respiratory syndrome patients. Am. J. Pathol. 170, 538-545.

Yen, Y.T., Liao, F., Hsiao, C.H., Kao, C.L., Chen, Y.C., and WuHsieh, B.A. (2006). Modeling the early events of severe acute respiratory syndrome coronavirus infection in vitro. J. Virol. 80, 2684-2693. 
Yount, B., Roberts, R.S., Sims, A.C., Deming, D., Frieman, M.B., Sparks, J., Denison, M.R., Davis, N., and Baric, R.S. (2005). Severe acute respiratory syndrome coronavirus group-specific open reading frames encode nonessential functions for replication in cell cultures and mice. J. Virol. 79, 1490914922.
Yuan, X., Wu, J., Shan, Y., Yao, Z., Dong, B., Chen, B., Zhao, Z., Wang, S., Chen, J. and Cong, Y. (2006). SARS coronavirus 7 a protein blocks cell cycle progression at G0/G1 phase via the cyclin D3/pRb pathway. Virology 346, 74-85.

Received May 17, 2007; accepted August 3, 2007 